\title{
GIDA ENDÜSTRİSI PROSES ATIKLARININ KOMPOSTLANMASINDA FARKLI KATKI MADDELERİ VE AŞI KULLANIMI
}

\author{
Selnur UÇARO ĞLU* \\ Behice Gamze GÜMRAH*
}

Alınma: 25.07.2016; düzeltme: 24.08.2016; kabul: 05.10.2016

Öz: Bu çalışmada; gıda endüstrisi proses atıklarının geri kazanımı ve bertarafı için farklı katkı maddeleri kullanılarak kompostlanabilirliği ve aşı olarak kullanılan arıtma çamurlarının kompostlamaya etkisinin belirlenmesi amaçlanmıştır. Proses atıklarına düzenleyici ve hacim arttıııı katkı maddesi olarak ayçiçeği sapı ve mısır koçanı karıştııılmıştır. Gıda endüstrisi proses atıklarının kompostlanabilirliğini araştırmak amacıyla dört farklı kompost karışımı hazırlanmıştır. Birinci karışıma (M1) 3:2 oranında proses atığı ve ayçiçeği sapı, ikinci karışıma (M2) 3:1:2 oranında proses atığ1, arıtma çamuru ve ayçiçeği sapı, üçüncü karışıma (M3) 3:1:2 oranında proses atığı, arıtma çamuru ve mısır koçanı, dördüncü karışıma (M4) ise 3:1:3 oranında proses atığı, arıtma çamuru ve mısır koçanı karıştııılmıştır. M1 karışımı, aşı ilave edilmeden kontrol karışımı olarak hazırlanmıştır. 28 günlük kompost denemeleri boyunca sıcaklık, kuru madde içeriği, organik madde kayıpları, $\mathrm{C} / \mathrm{N}$ oranı, $\mathrm{pH}$ ve elektriksel iletkenlik parametreleri izlenmiştir. Proseste oluşan en yüksek OM kaybı ve en yüksek sıcaklık M3 reaktöründe gözlenmiştir. Elde edilen sonuçlara göre proses atığının kompostlanmasında arıtma çamurunun aşı ve mısır koçanının ise katkı maddesi olarak 3:1:2 oranında kullanılmasıyla verimli bir kompostlama süreci gerçekleştiği tespit edilmiştir.

Anahtar Kelimeler: Arıtma çamuru, Aşı, Gıda endüstrisi proses atığı, Katkı maddesi, Kompostlama

\section{Use of Different Bulking Agents and Inoculation Agent in Composting of Food Industry Process Wastes}

\begin{abstract}
The aim of this study was to investigate the compostability of food industry process wastes with different bulking agents for disposal and recovery, and to determine the effect of treatment sludge which was used as inoculation agent. Sunflower stalk and corn cob were mixed to process wastes as bulking agents. Four different compost mixtures were prepared to investigate composting of process wastes. Process wastes and sunflower stalk to first mixture (M1) at ratio of 3:2; process wastes, treatment sludge and sunflower stalk to second mixture (M2) at ratio of 3:1:2; process wastes, treatment sludge and corn cob to third mixture (M3) at ratio of 3:1:2; process wastes, treatment sludge and corn cob to fourth mixture (M4) at ratio of 3:1:3 were added. M1 mixture was prepared without inoculation agent as control mixture. Temperature, dry matter content, organic matter loss, $\mathrm{C} / \mathrm{N}$ ratio, $\mathrm{pH}$ and electrical conductivity parameters were monitored during the composting process for 28 days. The highest organic matter losses and the highest temperature formed in the process were monitored in M3 reactor. According to the results, for the efficiently composting process; process wastes with treatment sludge as inoculation agent and corn cob as bulking agent at ratio of 3:1:2 were determined.
\end{abstract}

Keywords: Treatment sludge, Inoculation Agent, Food industry process waste, Bulking agent, Composting

\footnotetext{
* Uludağ Üniversitesi, Mühendislik Fakültesi, Çevre Mühendisliği Bölümü, 16059, Nilüfer/ BURSA İletişim Yazarı: Selnur UÇAROĞLU (selnur@uludag.edu.tr)
} 


\section{GİRIŞ}

Gıda atıkları dünyada birçok ülkede büyük miktarlarda oluştuğundan dolayı problem yaratan biyobozunur katı atıklardır. Yüksek oranda uçucu organik madde ve nem içeriği nedeniyle, düzensiz depolama, bertaraf, toplama ve taşıma sırasında koku ve sızıntı suyu gibi ciddi çevresel problemlere neden olabilirler ( $\mathrm{Li}$ ve diğ., 2013). Gıda fabrikalarında, proses sonucunda yan ürün olarak çok fazla miktarda gıda atıkları oluşmakta ve bunların bir çoğu anında imha edilmekte ya da daha düşük teknolojiler kullanılarak ekonomik değeri az olan ürünlere (hayvan yemi, gübre, vb.) dönüştürülmektedir. Gıda işleme sırasında ortaya çıkan atıkların etkili bir şekilde değerlendirilmesi, yalnız çevre kirliliğinin önlenmesi amacıyla değil, katma değer yaratılması ve ürünlerin çeşitlendirilmesi amacıyla da önemlidir (Yağc1 ve diğ., 2006). Günümüzde, gelişmekte olan ülkelerdeki nüfusun $\% 15$ 'i açlıkla beraber aşırı gıda tüketimi, gıdadan kaynaklanan hastalıklar ve gıda atıklarının aşırı üretimi ile uğraşmaktadır. Besin zincirinin kaçınılmaz bir parçası olan ve kullanıldıktan sonra atık haline dönüşen gıda ürünleri dünya genelinde bir endişe konusudur (Mirabella ve diğ., 2014). Bu nedenle atıkların toplanması ve bertarafı insan sağlığı, çevre kirliliği ve ülke ekonomisi açısından önem arz etmektedir. Bu atıkların bertarafı ve geri kazanımı içim kompostlama etkili bir yöntemdir.

Günümüzde tarımsal alanları çevresel açıdan güvenli şekilde korumak amacıyla sürdürülebilir bir strateji olarak kompostlama işlemi kullanılmaktadır. Bu yöntem, karbon emisyonlarını azaltmak ve arazide kullanımını geliştirmek amacıyla uygun bulunmaktadır. Bu sayede farklı organik atıklar tarımda kullanılmak üzere ve uygun koşullar sağlanarak geri dönüştürülebilir (Wang ve diğ., 2015). Kompostlama biyolojik parçalanabilir organik atıklardan organik gübre elde etmek için kullanılan çevre dostu bir yöntemdir (Choy ve diğ., 2015). Zengin organik içeriğe sahip gıda atıklarının kompostlaması konusunda birçok araştırmacı çalışma yapmıştır (Al-jabi ve diğ., 2008; Chang ve Chen, 2010; Cheung ve diğ., 2010). Kompostlama süresini kısaltmak ve ürün kalitesini arttırmak amacıyla kompostlama işleminde gıda atıkları ile birlikte çeşitli katkı maddeleri kullanılır. Kullanılan katkı maddeleri hacim arttırıcı özellikte olup yüksek karbon içeriğine sahip olduklarından kompost için uygun $\mathrm{C} / \mathrm{N}$ oranını da sağlar (Choy ve diğ., 2015). Bununla birlikte gıda atıklarının karakteristik özellikleri olan yüksek nem içeriği, asitlik, yüksek yağ ve tuzluluk oranı parçalanma sürecini geciktirebilir (Chan ve diğ., 2016). Katk1 maddeleri ile beraber aşı ilavesi yapılarak da verim arttırılır ve kompostlama zamanı kısaltılabilir. Kompost karışımına ilave edilen aşı ortamdaki yararlı mikroorganizma miktarını arttırır. Bu sayede biyolojik parçalanma işlemi hızlanır ve kompostlama zamanı kısaltılmış olur (Cao ve diğ.,2013). Biyolojik ayrışma prosesi olan kompostlama için mikrobiyal aktiviteyi etkileyen kontrol parametreleri ve organik madde parçalanması önemli faktörlerdir. Mikrobiyal aktivite ve organik madde stabilizasyonu için uygun değerlerde tutulması gereken bu parametreler sıcaklık, pH, C/N oranı ve nem içeriğidir (Nikaeen ve diğ., 2015).

Bu çalışmada gıda endüstrisi proses atıkları (PA), katkı maddesi olarak ayçiçeği sapı (AS) ve mısır koçanı (MK), aşı olarak gıda endüstrisine ait arıtma çamuru (AÇ) ilavesi yapılarak kompostlama işlemine tabi tutulmuştur. Dört ayrı kompost reaktörü hazırlanan çalışmada, kimyasal ve fiziksel parametrelerin değişimi incelenerek kompostlama prosesine aşı ve farklı katkı maddelerinin etkisini belirlemek amaçlanmıştır.

\section{MATERYAL VE YÖNTEM}

\subsection{Ham Malzemeler ve Deney Düzeneği}

Gıda endüstrisi proses atığı, iki farklı katkı maddesi ile birlikte dört ayrı aerobik reaktörde kompostlanmıştır. Çalışmada kompostlama prosesinin ana materyali olan PA, Bursa İl'inde faaliyet gösteren bir gıda işletmesinden alınmıştır. Gıda atıkları içeriğinde biber, domates, patlıcan, taze fasulye ve bamya bulunan, hasarlı ve bozulmuş olarak ayrılan atıklardır. Aşı maddesi olarak kullanılan AÇ, PA'nın temin edildiği gıda işleme fabrikasının atıksu arıtma 
tesisinden alınmıştır. Kompost karışımının uygun nem ve $\mathrm{C} / \mathrm{N}$ değerinin sağlanabilmesi için düzenleyici katkı maddesi olarak AS ve MK kullanılmıştır. Ayçiçeği sapı, Uludağ Üniversitesi Ziraat Fakültesi Çiftlikleri'nden temin edilmiştir. Mısır koçanı ise Bursa İl'inde bulunan mısır işleme tesisinden alınmıştır. Kullanılan AS ve MK, 0,5-1 cm boyutlarında öğütülmüştür.

Havalı kompostlama işlemi kesikli reaktörde gerçekleştirilmiştir (Şekil 1). Reaktörlere hava, 8 çıkışlı 1 adet akvaryum pompası vasıtasıyla, rotametreden geçirilip debisi ayarlanarak verilmiştir. Havalandırma, zaman ayarlayıcıya bağlı selenoid vana kullanılmak suretiyle 1 saatte 15 dakika 600-700 ml/dk hava verecek şekilde yapılmıştır. Havanın karışımın içine homojen olarak dağılmasını sağlamak için, reaktör tabanından $5 \mathrm{~cm}$ yükseklikte ızgara yerleştirilmiştir. Reaktörlerdeki sıcaklık verileri, sıcaklık sensörü vasıtasıyla ölçülmüştür. Atık kütlesinin sıcaklığını korumak, çevreyle 1sı alışverişini önlemek amacıyla reaktör yalıtım malzemesiyle kaplanmıştır. Reaktörler paslanmaz çelik malzemeden üretilmiş olup iç çap $300 \mathrm{~mm}$, et kalınlığ $10 \mathrm{~mm}$ ve yüksekliği $450 \mathrm{~mm}$ 'dir. Faydalı hacmi ise $30 \mathrm{~L}$ 'dir.

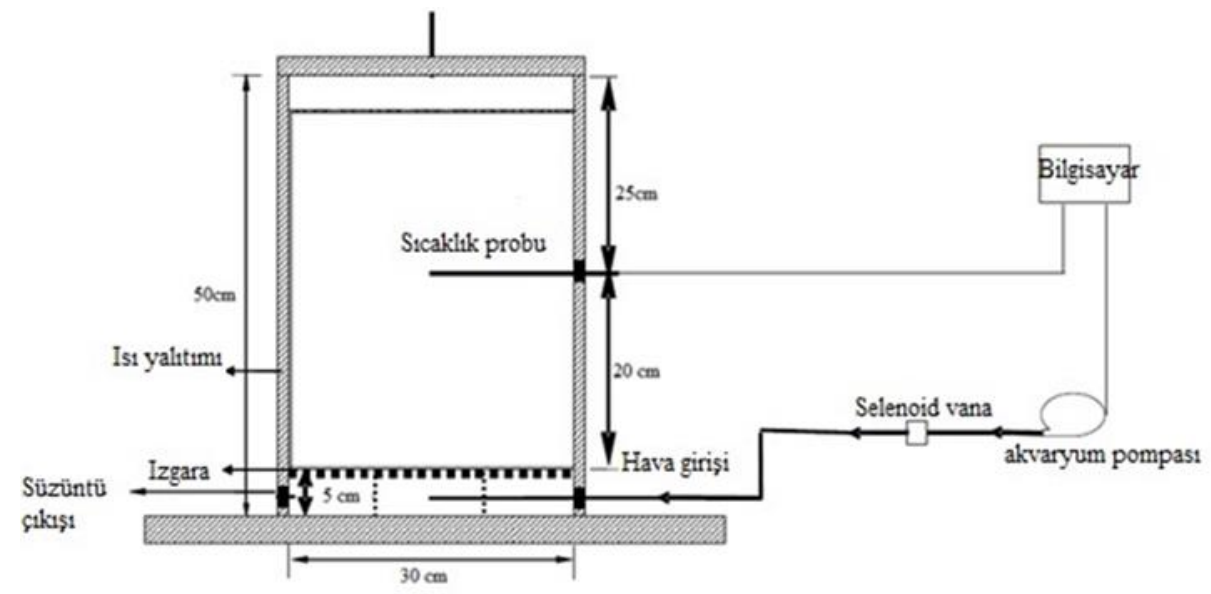

Şekil 1:

Kompost Sisteminin Şematik Gösterimi

\subsection{Yöntem}

Kompostlama işlemi, 4 ayrı reaktörde 28 gün süresince gerçekleştirilmiştir. M1 reaktörü PA ve katkı maddesi olarak AS, M2 reaktörü PA, aş1 olarak AÇ, katk1 maddesi olarak AS, M3 ve M4 reaktörü farklı oranlarda PA, AÇ ve MK karıştırılarak hazırlanmıştır. Tablo 1' de tüm reaktörlerin karışım reçeteleri verilmiştir. Tabloda belirtilen oranlarda M1 reaktörüne toplam 5 $\mathrm{kg}$, M2 reaktörüne 5,5 kg, M3 reaktörüne $10 \mathrm{~kg}$ ve M4 reaktörüne toplam 8,4 kg kompost malzemesi homojen bir şekilde karıştırılarak doldurulmuştur.

Tablo 1. Kompost Reaktörleri için Karışım Reçeteleri

\begin{tabular}{|l|l|l|l|l|}
\hline Karışımlar & $\begin{array}{l}\text { Proses } \\
\text { Atığ1* } \\
(\mathrm{PA})\end{array}$ & $\begin{array}{l}\text { Arıtma } \\
\text { Çamuru* } \\
\text { (AÇ) }\end{array}$ & $\begin{array}{l}\text { Ayçiçeği } \\
\text { Sap1* } \\
\text { (AS) }\end{array}$ & $\begin{array}{l}\text { Mısır } \\
\text { Koçan1* } \\
(\mathrm{MK})\end{array}$ \\
\hline M1 & 3 & - & 2 & - \\
\hline M2 & 3 & 1 & 2 & - \\
\hline M3 & 3 & 1 & - & 2 \\
\hline M4 & 3 & 1 & - & 3 \\
*Nemli ağırlık esas alınmıştır.
\end{tabular}


Kompost karışımlarının homojenliğini sağlamak ve havalandırmak için reaktörler gün aşırı ve örnek alma günlerinde $(0,2,7,14,21$ ve 28. gün) manuel olarak karıştırılmıştır. Kompostlama prosesinde her dakikada 3 veri olacak şekilde sıcaklık ve hava değerleri SCADA programı ile 28 gün boyunca kaydedilmiştir.

\subsection{Analiz Yöntemleri}

Reaktörlere konulan karışımlardan 0, 2, 7, 14, 21 ve 28. günlerde örnekler alınmış ve deneysel çalışmalar yapılmıştır. Kompost karışımlarından alınan örneklerdeki katı madde (KM) miktarı $105^{\circ} \mathrm{C}$ 'de kurutulan örneklerdeki ağırlık kaybı, uçucu madde miktarı da $550^{\circ} \mathrm{C}$ 'de yanma kaybı dikkate alınarak hesaplanmıştır (APHA, AWWA, WEF, 1998). KM miktarı 100'den çıkartılarak nem miktarı hesaplanmıştır. Uçucu madde miktarı organik madde (OM) olarak kabul edilmiştir (Okalebo ve diğ., 1993; Diaz ve diğg. 2007; Khalil ve diğ., 2011). OM kayıpları, proses başlangıcı ve proses sonundaki OM içerikleri esas alınarak denklem (1) ile hesaplanmiştır (Haug, 1993);

$$
K=\frac{\left[\left(O M_{b}-O M_{s}\right) 100\right]}{\left[O M_{b}\left(100-O M_{s}\right)\right]}
$$

$O M_{b}$ : Proses başlangıcındaki OM

$O M_{S}$ : Proses sonundaki OM

Kompostlamada kullanılan ham malzemelerin ve kompost karışımlarının kolay okside olabilir organik karbon konsantrasyonları, örneklerin OM içerikleri baz alınarak 1,83 faktörü kullanılarak $(\% \mathrm{C}=(100-\%$ kül $) / 1,83)$ hesaplanmıştır (Barrington ve diğ., 2002). Kompost karışımından alınan örneklerin $\mathrm{pH}$ ve elektriksel iletkenlik (EC) değerleri 1:10 saf su ekstraktında belirlenmiştir (Rhoades, 1982; Mc Lean, 1982). Amonyum ve nitrat azotu konsantrasyonunun belirlenmesi için örnekler $2 \mathrm{M} \mathrm{KCl}$ ile ekstrakte edilmiş, esktraktlardaki konsantrasyonlar $\mathrm{MgO}$ ve devarda alaşımı kullanılmak suretiyle su buharı destilasyonu ve titrasyon yoluyla ölçülmüsstür (Keeney ve Nelson, 1982). Toplam azot içeriğinin belirlenmesi için Kjedahl yöntemiyle yakma yapılmış ve toplam azot konsantrasyonu (TKN) su buharı destilasyonu ile belirlenmiştir (Bremner ve Mulvaney, 1982).

\section{BULGULAR VE TARTIŞMA}

\subsection{Kompost Materyallerinin ve Başlangı̧̣ Kompost Karışımlarının Karakterizasyonu}

Aerobik kompost reaktörlerine yerleştirilen ham materyaller (PA, AÇ, AS, MK) ve kompost karışımlarının başlangıç özellikleri Tablo 2'de verilmiştir. Kompostlama işlemine tabi tutulacak olan PA, yüksek nem içeriğine $(\% 93,2)$ ve düşük $\mathrm{C} / \mathrm{N}$ oranına $(14,8)$ sahiptir. $\mathrm{Bu}$ değerler verimli bir kompost prosesi yürütmek için uygun değildir (Uçaroğlu, 2014). Bu nedenle bu hammaddeden kompost elde edilebilmesi için nem ve $\mathrm{C} / \mathrm{N}$ oranını düzenleyen katkı maddesi ile karıştırılması gerekli olmuştur. Düşük nem ve yüksek karbon içeren katkı malzemeleri (AS ve MK) ile hazırlanan kompost karışımlarının (M1, M2, M3 ve M4) başlangıçtaki nem ve C/N değerleri literatürde belirtilen uygun değerlere getirilmiştir (Nikaeen ve diğ., 2015). Arıtma çamuru ise kompost karışımı içerisindeki parçalanmayı gerçekleştirecek olan mikroorganizmaları arttırmak amacıyla aşı maddesi olarak karıştırılmıştır. Aynı zamanda AÇ, yüksek azot içeriğinden $(\% 5,73)$ dolayı karışımların $\mathrm{C} / \mathrm{N}$ oranlarını da ayarlamada rol oynamıştır. Hazırlanan kompost karışımlarının organik madde içerikleri (yaklaşık \%90) oldukça yüksektir. Reaktörlerdeki başlangıç nem seviyesi \%57,2 ile \%71,4 arasındadır.

Tablo 2. Ham Materyal ve Kompost Karışımlarının Başlangıç Özellikleri 


\begin{tabular}{|c|c|c|c|c|c|c|c|c|}
\hline Parametre & $\begin{array}{c}\text { Gıda } \\
\text { Endüstrisi } \\
\text { Proses } \\
\text { Atığı (PA) }\end{array}$ & $\begin{array}{c}\text { Arıtma } \\
\text { Çamuru } \\
\text { (AÇ) }\end{array}$ & $\begin{array}{c}\text { Ayçiçeği } \\
\text { Sapı } \\
\text { (AS) }\end{array}$ & $\begin{array}{c}\text { Mısır } \\
\text { Koçanı } \\
\text { (MK) }\end{array}$ & $\begin{array}{c}\text { M1 } \\
\text { Kompost } \\
\text { Karışımı }\end{array}$ & $\begin{array}{c}\text { M2 } \\
\text { Kompost } \\
\text { Karışımı }\end{array}$ & $\begin{array}{c}\text { M3 } \\
\text { Kompost } \\
\text { Karışımı }\end{array}$ & $\begin{array}{c}\text { M4 } \\
\text { Kompost } \\
\text { Karışımı }\end{array}$ \\
\hline $\begin{array}{c}\text { pH (1:10, } \\
\text { saf su } \\
\text { ekstraktı) }\end{array}$ & $6,68 \pm 0,13$ & $6,90 \pm 0,01$ & $6,70 \pm 0,01$ & $5,16 \pm 0,00$ & $6,54 \pm 0,11$ & $6,85 \pm 0,14$ & $5,96 \pm 0,03$ & $6,11 \pm 0,05$ \\
\hline $\begin{array}{c}\text { EC, mS/cm } \\
\text { (1:10, saf } \\
\text { su } \\
\text { ekstraktı) }\end{array}$ & $4,02 \pm 0,04$ & $3,83 \pm 0,00$ & $0,20 \pm 0,00$ & $3,08 \pm 0,01$ & $2,55 \pm 0,10$ & $2,67 \pm 0,12$ & $2,04 \pm 0,04$ & $1,69 \pm 0,08$ \\
\hline $\begin{array}{c}\text { Kuru } \\
\text { Madde, \% }\end{array}$ & $6,79 \pm 0,63$ & $11,7 \pm 0,07$ & $89,7 \pm 0,12$ & $87,8 \pm 0,24$ & $30,3 \pm 0,95$ & $28,6 \pm 5,86$ & $34,4 \pm 3,41$ & $42,8 \pm 2,78$ \\
\hline $\begin{array}{c}\text { Nem, \% } \\
\text { OM, \% }\end{array}$ & $93,2 \pm 0,63$ & $88,3 \pm 0,07$ & $10,3 \pm 0,12$ & $12,2 \pm 0,24$ & $69,7 \pm 0,95$ & $71,4 \pm 5,86$ & $65,6 \pm 3,41$ & $57,2 \pm 2,78$ \\
\hline TKN, \% & $3,53 \pm 0,57$ & $5,73 \pm 0,11$ & $0,48 \pm 0,04$ & $0,50 \pm 0,02$ & $1,01 \pm 0,19$ & $1,02 \pm 0,03$ & $1,11 \pm 0,57$ & $0,87 \pm 1,10$ \\
\hline C/N Oranı & 14,8 & 6,23 & 104,3 & 104,9 & 47,9 & 47,8 & 44,4 & 56,5 \\
\hline
\end{tabular}

\subsection{Sicaklık}

Reaktörlerdeki sıcaklık ve ortam sıcaklık değişimleri Şekil 2'de gösterilmiştir. Genel olarak dört reaktörde de sıcaklık, termofilik faz seviyelerine $\left(>40^{\circ} \mathrm{C}\right)$ yükselmiştir. Sicaklığın, AS'nın katk1 maddesi olarak kullanıldığı M1 reaktöründe maksimum $44{ }^{\circ} \mathrm{C}$ 'ye, katk1 maddesi olan AS'nın yanında aşı olarak AÇ'nun kullanıldığı M2 reaktöründe $52,6{ }^{\circ} \mathrm{C}$ 'ye, MK'nın farklı oranlarda katkı maddesi olarak kullanıldığı aşı1ı M3 ve M4 reaktörlerinde sirasıyla $67,3{ }^{\circ} \mathrm{C}$ ve $66,7{ }^{\circ} \mathrm{C}^{\prime}$ ye ulaştı̆̆ 1 gözlenmiş̧tir. Kompost reaktörlerindeki sıcaklıklar, ortamda kompost substratlarının yeterli miktarda bulunması ve kompost karışımlarındaki organik maddelerin mikroorganizmalar tarafindan parçalanmasıyla yükselmektedir (Haug, 1993). M1 ve M2 reaktörü karşılaştırıldığında, M2 reaktörüne aşı ilavesi ile mikrobiyal aktivitenin arttırıldığı, bu sayede sıcaklığın daha fazla yükseldiği ve organik madde parçalanmasının arttırıldığ 1 tespit edilmiştir (Adhikari ve diğ., 2009). Aş1 ilavesinin kompostta olumlu etkisi tespit edildikten sonra, farklı bir katk1 maddesi olan MK'nın kullanıldığı, aşı ilaveli M3 ve M4 reaktörlerinde, sıcaklık önemli oranda yükselmiştir. Uçaroğlu ve Alkan (2016) tarafından yapılan arıtma çamurlarının kompostlanabilirliğinin araştırıldığı çalışmada da benzer şekilde MK'nın katkı maddesi olarak kullanıldığı kompost karışımında en yüksek sıcaklık elde edilmiştir. Kompost karışımlarındaki sıcaklık değişimlerini kontrol eden ana mekanizmanın kolay parçalanabilir organik madde miktarı ile ilgili olduğu söylenebilir. Bu çalışmada sıcaklık parametresi göz önünde tutulduğunda, M3 ve M4 reaktörlerinde kullanılan MK'nın, M1 ve M2 reaktörlerinde kullanılan AS'na göre daha kolay parçalanabilir organik madde içerdiği ve PA'nın kompostlanmasında MK'nın katkı maddesi olarak kullanımının kompost proses verimini daha fazla yükselttiği belirlenmiştir.

Önemli oranda patojen kontrolü için atıklar reaktörde en az 5 gün $40{ }^{\circ} \mathrm{C}$ 'nin üzerinde kalmalıdır ve bu süre içinde sıcaklık 4 saat boyunca $55^{\circ} \mathrm{C}^{\prime}$ yi aşmalıdır (USEPA, 1993). Ülkemizde, 5 Mart 2015 tarihinde 29286 tarihli Resmi Gazete' de yayınlanan Kompost Tebliği'nde ise elde edilen kompost ürününün toprak iyileştirici malzeme olarak kullanılabilmesi için sicaklık değeri kesintisiz 2 hafta $55{ }^{\circ} \mathrm{C}, 60{ }^{\circ} \mathrm{C}$ 'de ise 1 hafta öngörülmektedir (KT, 2015). M1 reaktöründe sıcaklık 1 gün $40{ }^{\circ} \mathrm{C}$ 'nin üzerinde kalmıştır, 
ancak $55{ }^{\circ} \mathrm{C}$ 'ye ulaşamamıştır. M2 reaktöründe sıcaklık 3 gün 5 saat $40{ }^{\circ} \mathrm{C}$ 'nin üzerinde kalmıştır, ancak bu reaktör de $55^{\circ} \mathrm{C}$ 'ye ulaşamamıştır. M3 reaktöründe ise sicaklık yaklaşı 12 gün $40{ }^{\circ} \mathrm{C}$ 'nin üzerinde kalmıştır ve bu süre içinde 7 gün 4 saat $55^{\circ} \mathrm{C}$ 'yi aşmıştır. Yine aynı süre içinde 2 gün 9 saat $60^{\circ} \mathrm{C}^{\prime}$ nin üzerinde kalmıştır. Benzer şekilde M4 reaktöründe ise sıcaklık 10 gün 18 saat $40^{\circ} \mathrm{C}$ ' nin üzerinde kalmıştır ve bu süre içinde 3 gün 13 saat $55^{\circ} \mathrm{C}^{\prime}$ yi aşmıştır. Aynı süre içinde 1 gün 14 saat $60{ }^{\circ} \mathrm{C}$ 'nin üzerinde kalmıştır. Bu sonuçlar değerlendirildiğinde M3 ve M4 reaktörlerinden elde edilen kompostun EPA Kriterlerine göre toprak iyileştirici malzeme olarak kullanılabilmesi için önemli oranda patojen giderimi elde edilebilmiştir. Her iki reaktörde de Kompost Tebliği'nde hijyenizasyon ve patojen giderimi için belirtilen sıcaklık şartları sağlanamamıştır. Bu çalışma, laboratuvar ölçekli bir reaktörde gerçekleştirilmiş olup, reaktörler sınırlı miktarda substrat içermektedir. Büyük ölçekli kompost tesislerinde yeterli miktarda substrat olacağından dolayı M3 ve M4 karışımlarının Kompost Tebliği'ndeki sıcaklık değerlerine ulaşabileceği düşünülmektedir. M1 ve M2 reaktörleri için ise Kompost Tebliği ve EPA kriterleri göz önüne alındığında elde edilen kompostun toprak iyileştirici malzeme olarak kullanılabilmesi için gerekli hijyenizasyon her iki karışımda da elde edilememiştir.
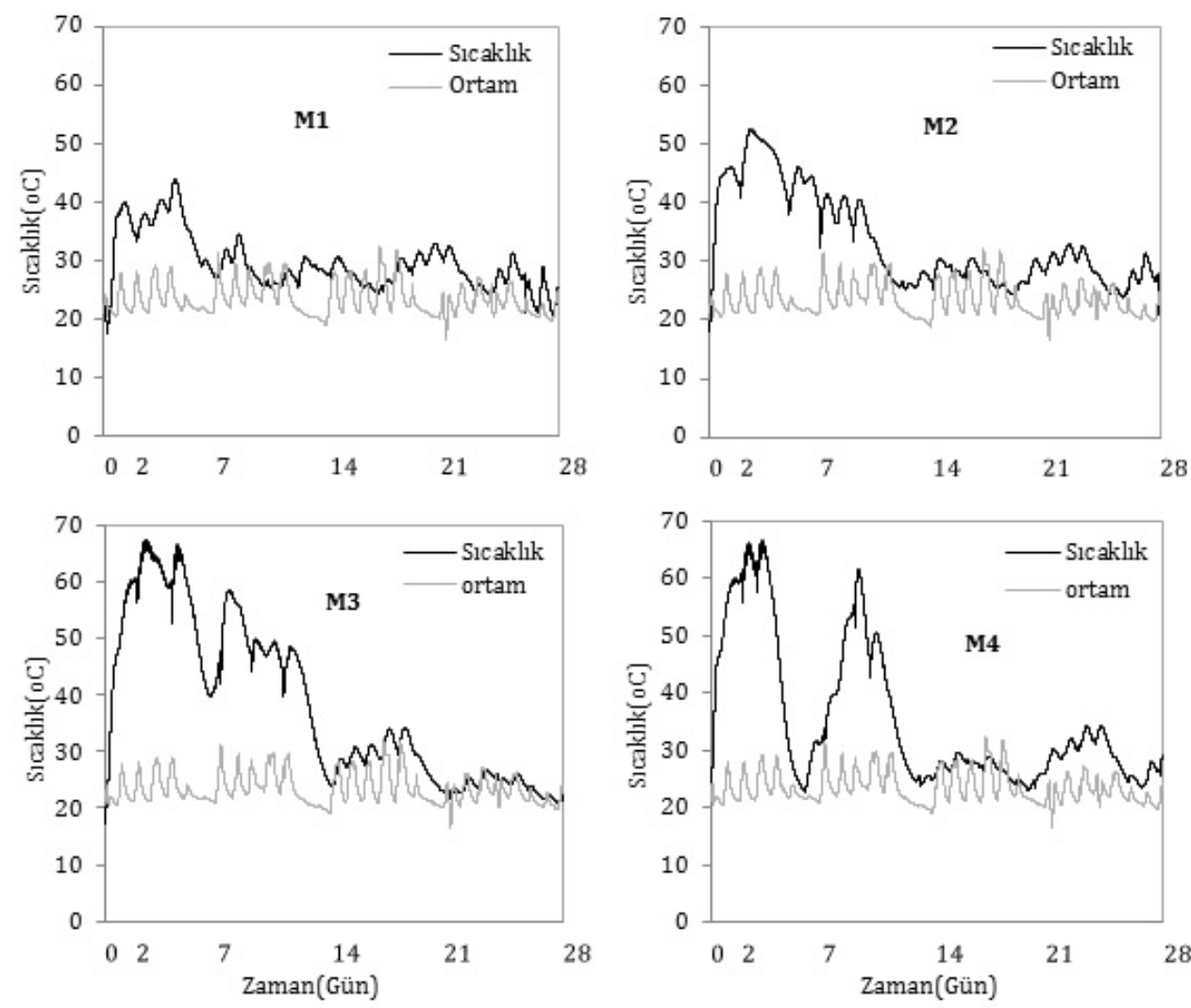

Şekil 2:

Reaktörlerdeki Sicaklık Değişimleri

\subsection{Aşı İlavesi ve Farklı Katkı Maddelerinin Fiziksel ve Kimyasal Parametrelerin Değişimi Üzerine Etkisi}

$\mathrm{pH}$, kompost prosesini etkileyen önemli bir parametredir. Bu çalışmada kompost prosesi boyunca, pH değeri M1 reaktöründe 6,5 ile 9,5 arasında, M2 reaktöründe 6,9 ile 9,8 arasında, M3 reaktöründe 5,9 ile 7,8 arasında ve M4 reaktöründe 6,1 ile 7,6 arasında değişmiştir. Şekil 3a incelendiğinde tüm reaktörlerde $\mathrm{pH}$ değerinde artış olduğu görülmektedir. $\mathrm{pH}$ değerinin, proses 
başlangıcında nötr değere yakın olan M1 ve M2 reaktörlerinde artış göstererek proses sonunda bazik değerlere yaklaştığı, proses başlangıcında zayıf asidik değerlere yakın olan M3 ve M4 reaktörlerinde ise proses sonunda nötr değerlerde olduğu gözlenmiştir. Reaktörlerin tümünde gerçekleşen artış proses sırasında oluşan amonyağın suda çözünmesiyle alkali amonyum formlarına dönüşmesi olarak açıklanabilir (Wang ve diğ., 2015; Choy ve diğ., 2015). M3 ve M4 reaktörlerinde $\mathrm{pH}$ değerinin bir süre geçtikten sonra azalmaya başlamasının sebebi ise mikrobiyal aktivite sonucu organik asitlerin oluşması ile açılanmaktadır (Wang ve diğ., 2015). Yapılan bir çalışmada kompost ürünü için en uygun $\mathrm{pH}$ değerinin 7- 8 aralığında olduğu belirtilmiştir (Chan ve diğ., 2016). Ülkemizde Kompost Tebliği'nde verilen değer 5,5 ile 8,5 aralığındadır. Bu çalışmada M1 ve M2 reaktörlerindeki kompost ürününün $\mathrm{pH}$ değeri standardın üzerinde bulunurken M3 ve M4 reaktörlerindeki kompost ürünün $\mathrm{pH}$ değerinin standarda uygun olduğu belirlenmiştir.

Elektriksel iletkenlik çözünmüş tuz konsantrasyonunun göstergesi olduğundan dolay1 kompostlama prosesi için önemli bir parametredir. Tüm reaktörlerin elektriksel iletkenliğinin zamana bağlı değişimi Şekil 3b'de gösterilmektedir. EC değerleri tüm reaktörlerde 1,4 ile 3,5 arasında değişmiştir. Tüm reaktörlerde EC değeri artış eğilimindedir. Bu artışın sebebi biyolojik parçalanma sonucunda kütle azalması ve mineral tuzlarının (örn. fosfat iyonları) daha fazla açığa çıkmasıdır (Kalemelawa ve diğ., 2012; Kumar ve diğ., 2010; Yu ve Huang, 2008). Yapılan bir çalışmada kompost ürününün $\mathrm{EC}$ değerinin $4 \mathrm{mS} / \mathrm{cm}$ değerinden yüksek olması durumunda toprakta olumsuz etki yaratacağı belirtilmiştir (Yang ve diğ., 2015). Bu çalışmada elde edilen kompost ürünlerinin EC değerleri toprak için uygun değerlerdir.
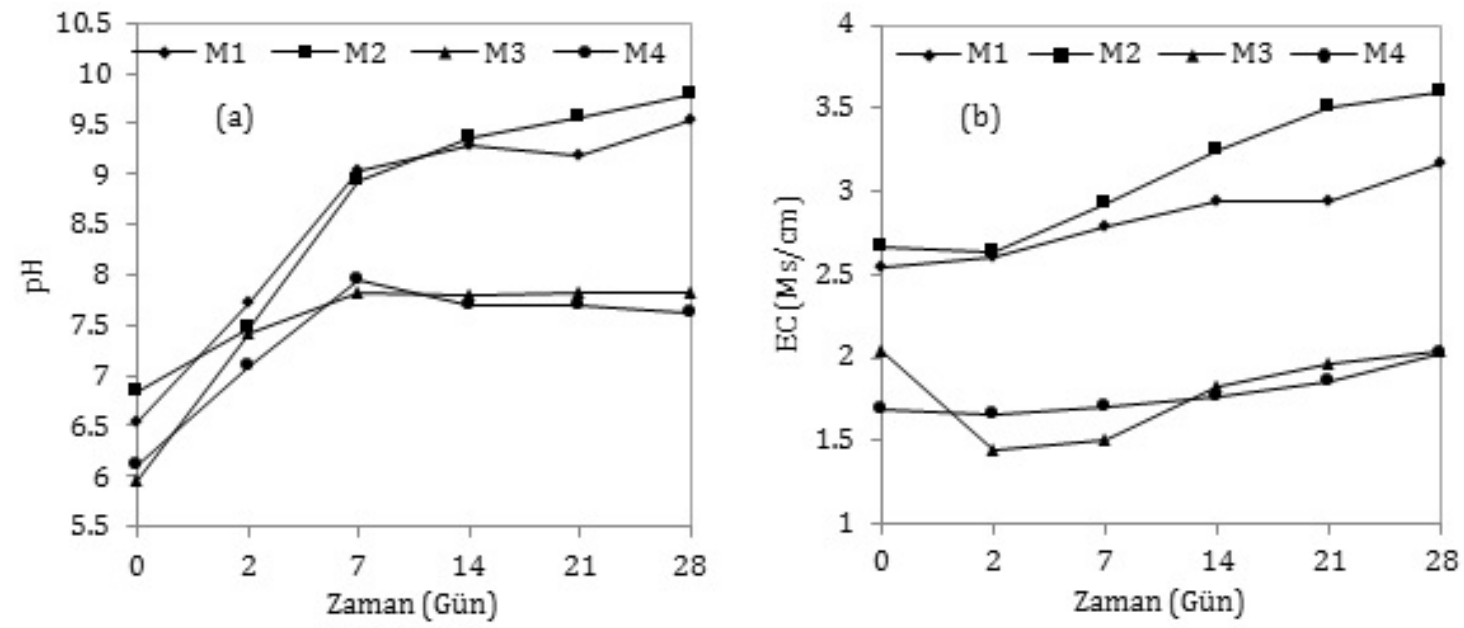

Şekil 3.

Reaktörlerdeki pH ve EC Değişimleri

Organik madde bozunmas1, direkt olarak mikrobiyal respirasyon ile ilgili olup organik madde kayıplarını oluşturur (Paredes ve diğ., 2002). Biyobozunur organik madde kayıpları, kompost prosesi boyunca \% 30 ile \% 60 arasında gerçekleşmektedir (Diaz ve diğ.,2007). Kompostlama prosesinde OM kayıpları sıcaklık artışıyla doğru orantılı olarak gerçekleşir (Yang ve diğ., 2015). Reaktörlerin zamana bağlı organik madde değişimi Şekil 4a'da gösterilmektedir. Şekil 4a incelendiğinde tüm reaktörlerde organik madde içeriğinin azaldığı görülmektedir. Reaktörlerde gerçekleşen OM kayıpları hesaplandığında M1 reaktöründe \% 35,6, M2 reaktöründe $\% 52,3, \mathrm{M} 3$ reaktöründe $\% 64,3$ ve M4 reaktöründe ise $\% 52,0$ bulunmuştur. M3 reaktöründe en fazla mikrobiyal faaliyetin gerçekleştiği ve diğer reaktörlere göre daha fazla OM kayb1 meydana geldiği tespit edilmiştir. Aş1 kullanılan M2 ve M4 reaktörlerinde de, aş1 kullanılmayan M1 reaktörüne göre oldukça fazla OM kaybı gerçekleşmiştir. Aşı kullanımının ve 
katkı maddesi olarak MK kullanımının AS kullanımına nazaran mikrobiyal aktiviteyi ve bununla beraber OM kayıplarını arttırdığı tespit edilmiştir.

Kompostlama prosesinde kaliteli bir ürün elde edilebilmesi için önemli faktörlerden biri de organik atığın $\mathrm{C} / \mathrm{N}$ oranıdır. Kompostlama sürecinde reaktörlerdeki $\mathrm{C} / \mathrm{N}$ oranının zamana bağlı değişimi Şekil 4b'de gösterilmiştir. Reaktörlerdeki $\mathrm{C} / \mathrm{N}$ oranının başlangıç değerleri M1 reaktöründe 47,9, M2 reaktöründe 47,8, M3 reaktöründe 37,9 ve M4 reaktöründe ise 34,1'dur. M1, M2, M3 ve M4 reaktörleri için C/N değerleri proses sonunda sirasıyla \% 2,1, \% 30,2, \% 61,1 ve $\% 42,5$ oranlarında azalarak, 46,8,33,3, 14,7 ve 19,6 değerlerine düşmüştür. $\mathrm{Bu}$ sonuçlar değerlendirildiğinde katkı maddesi olarak MK kullanılan ve aşı ilavesi yapılan M3 reaktöründe mikrobiyal aktivitenin hızlı gerçekleştiği tespit edilmiştir. Katkı maddesi olarak MK kullanımı ve aşı ilavesiyle, organik madde parçalanması arttırılmış olup $\mathrm{C} / \mathrm{N}$ oranında daha fazla azalma meydana gelmiştir. En düşük $\mathrm{C} / \mathrm{N}$ azot azalması katkı maddesi olarak ayçiçeği sapı kullanılan ve aşı ilavesi yapılmayan M1 reaktöründe gerçekleşmiştir. Kompost Tebliği'ne göre kompost ürününün $\mathrm{C} / \mathrm{N}$ oranı 10-30 aralığında olmalıdır. $\mathrm{Bu}$ çalışmada $\mathrm{M} 1$ ve $\mathrm{M} 2$ reaktörlerinde proses sonunda, $\mathrm{C} / \mathrm{N}$ oranı tebliğde istenilen değerlerin üzerinde olup $\mathrm{M} 3$ ve M4 reaktörlerinde ulaşılan $\mathrm{C} / \mathrm{N}$ oranları, tebliğde istenilen değer aralığındadır.

$\mathrm{Bu}$ çalışmada incelenen parametreler için, tüm kompost karışımlarının 28. günlerinde elde edilen değerlerinin Kompost Tebliği ile karşılaştırmaları Tablo 3 'te özetlenmiştir.
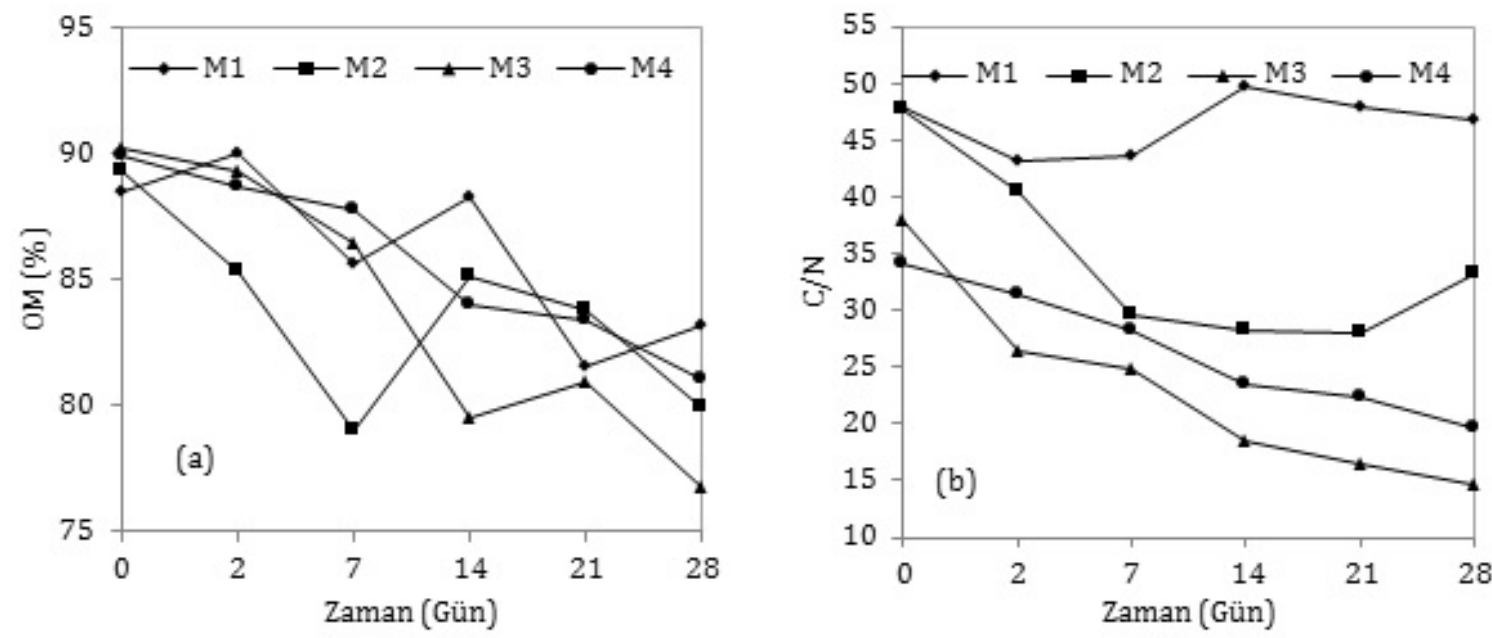

Şekil 4.

Reaktörlerdeki OM içeriğinin ve C/N oranının zamana bağlı değişimi.

\section{SONUÇLAR}

$\mathrm{Bu}$ çalışmada gıda endüstrisi proses atıklarının kompostlanmasında farklı katkı maddeleri ve aşının etkisi araştırılmıştır. Düzenleyici katkı maddesi olarak mısır koçanı ve ayçiçeği sapı kullanılmış olup aşı olarak gıda endüstrisi arıtma tesisinden kaynaklanan arıtma çamuru ilave edilmiştir. Bu çalışmanın sonuçları, mısır koçanı ve aşı kullanılarak hazırlanan M3 ve M4 reaktörlerinde en yüksek sıcaklıklara $\left(67,3{ }^{\circ} \mathrm{C}\right.$ ve $\left.66,7^{\circ} \mathrm{C}\right)$ ulaşıldığını ve bunun sonucunda önemli mikrobiyal stabilizasyonun sağlandığını göstermiştir. Ayrıca, en yüksek OM kayıpları $(\% 64,3$ ve \%52,0) ve en yüksek C/N azalması $(\% 61,1$ ve \%42,5) bu reaktörlerde elde edilmiştir. Katk1 maddesi olarak ayçiçeği sap1 ile hazırlanan kompost karışımlarında, aşı kullanılan M2 reaktöründe, aşı kullanılmayan M1 reaktörüne göre daha yüksek sıcaklık $\left(52,6^{\circ} \mathrm{C}\right.$ 'ye karş1 44 $\mathrm{C}^{\circ}$ ), daha yüksek OM kaybı (\% 52,3' ye karşı \% 35,6) ve daha fazla $\mathrm{C} / \mathrm{N}$ oranında azalma (\%30,2'ye karş1 \%2,1) elde edilmiştir. Bu sonuç, kompost prosesinde aş1 kullanımının 
mikrobiyal aktiviteyi ve verimliliği arttırdığını göstermiştir. Kullanılan katkı maddeleri içinde ise mısır koçanının kompostlama verimini önemli düzeyde arttırdığı tespit edilmiş ve iyi bir kompostun elde edilebilmesi için kullanımının uygun olduğu görülmüştür. Gıda endüstrisi proses atıklarının kompostlanmasında, en yüksek sıcaklık, OM kaybı ve $\mathrm{C} / \mathrm{N}$ azalması elde edilen aşı ve mısır koçanı kullanılan 3:1:2 oranında hazırlanan M3 reaktörünün, incelenen kompost kalite parametreleri göz önünde bulundurulduğunda, en uygun karışım olduğu tespit edilmiştir.

Tablo 3. Tüm Reaktörlerde İncelen Parametrelerin Kompost Tebliği ile Karşılaştırılması

\begin{tabular}{|c|c|c|c|c|c|}
\hline Parametre & $\begin{array}{c}\text { M1 } \\
\text { Kompost } \\
\text { Karışımı }\end{array}$ & $\begin{array}{c}\text { M2 } \\
\text { Kompost } \\
\text { Karışımı }\end{array}$ & $\begin{array}{c}\text { M3 } \\
\text { Kompost } \\
\text { Karışımı }\end{array}$ & $\begin{array}{c}\text { M4 } \\
\text { Kompost } \\
\text { Karışımı }\end{array}$ & $\begin{array}{c}\text { Kompost Tebliği } \\
\text { (EK 2) }\end{array}$ \\
\hline Sicaklık ( $\left.{ }^{\circ} \mathbf{C}\right)$ & 44 & 52,6 & 67,3 & 66,7 & $\begin{array}{l}\text { Kesintisiz olarak } \\
55^{\circ} \mathrm{C}^{\prime} \text { de 2 hafta, } \\
60^{\circ} \mathrm{C}^{\prime} \text { de 1 hafta, } \\
65^{\circ} \mathrm{C} \text { 'de 5 gün, } \\
70^{\circ} \mathrm{C} \text { 'de 1 saat, } \\
\text { İşlem görmüş olacaktır. }\end{array}$ \\
\hline $\begin{array}{c}\text { pH (1:10, saf su } \\
\text { ekstraktı) }\end{array}$ & $9,54 \pm 0,03$ & $9,79 \pm 0,02$ & $7,81 \pm 0,01$ & $7,61 \pm 0,01$ & $5,5-8,5$ \\
\hline C/N Oranı & 46,8 & 33,3 & 14,7 & 19,6 & $10-30$ \\
\hline
\end{tabular}

Gıda endüstrisine ait proses atıklarından mısır koçanı ve aşı ilavesi ile toprak iyileştirici malzeme ve nütrient kaynağı olarak tarımda kullanılabilecek stabilize kompost ürünü elde edilmesi Kompost Tebliği'nde ki tüm parametrelerin kontrol edilmesi ile mümkün olabilir. Bu çalışma ile kompost teknolojisinin, Türkiye'de kontrolsüz imha edilen veya daha düşük teknolojilerle ekonomik değeri az olan ürünlere (hayvan yemi, gübre vb.) dönüştürülen gıda endüstrisi proses atıklarının çevresel etkilerini en aza indirebilecek ve ekonomik değeri daha fazla olan kompost ürününe dönüştürebilecek bir teknoloji olduğu söylenebilir.

\section{TEŞEKKÜR}

Bu çalışmada, deneysel çalışmalardaki yardımlarından dolayı Barış Köksal ve Ecem Özdemir’e teşekkür ederiz.

\section{KAYNAKLAR}

1. Adhikari, B. K., Barrington, S., Martinez, J. and King, S. (2009) Effectiveness of three bulking agents for food waste composting, Waste Management, 29, 197-203. doi: 10.1016/j.wasman.2008.04.001

2. Al-jabi, L. F., Halalsheh, M. M. and Badarneh, D. M. (2008) Conservation of ammonia during food waste composting, Environmental Technology, 29, 1067-1073. doi:10.1080/09593330802175872

3. APHA, AWWA, WPCF, (1998). Standart Methods for the Examination of Water and Wastewater, Copyright by American Public Health Association, 20th edition, Baltimore, USA, 1269. 
4. Barrington, S., Choinière, D., Trigui, M., Knight, W. (2002) Effect of carbon source on compost nitrogen and carbon losses, Bioresource Technology, 83, 189-194. doi:10.1016/S0960-8524(01)00229-2

5. Bremner, J. M. and Mulvaney, C. S. (1982) Nitrogen-total in Methods of Soil Analysis, Part 2. Chemical and Microbiological Properties (ed A.L. Page), SSSA Book Series No 9, Soil Science Society of America and American Society of Agronomy, Madison, WI., 595-622.

6. Cao, W., Xu, H., Zhang, H. (2013) Architecture and functional groups of biofilms during composting with and without inoculation, Process Biochemistry, 48, 1222-1226. doi:10.1016/j.procbio.2013.06.015

7. Cheung, H. N. B., Huang, G. H., Yu, H. (2010) Microbial-growth inhibition during composting of food waste: effects of organic acids, Bioresource Technology, 101, 59255934. doi:10.1016/j.biortech.2010.02.062

8. Chang, J. I., Chen, Y. J. (2010) Effects of bulking agents on food waste composting, Bioresource Technology, 101, 5917-5924. doi:10.1016/j.biortech.2010.02.042

9. Chan, M. T., Selwam, A., Wong, J. W. C. (2016) Reducing nitrogen loss and salinity during 'struvite' food waste composting by zeolite amendment, Bioresource Technology, 200, 838-844. doi:10.1016/j.biortech.2015.10.093

10. Choy, S. Y., Wang, K., Qi W., Wang, B., Chen, C. L., Wang, J. Y. (2015) Co-composting of horticultural waste with fruit peels, food waste, and soybean residues, Environmental Technology, 36(11), 1448-1456. doi: 10.1080/09593330.2014.993728

11. Diaz, L. F., Bertoldi, M., Bidlingmaier, W., Stentiford, E. (2007) Compost Science and Technology, Elsevier Publishers, Issn 1478-7482, 8(51).

12. Haug, R.T. ( 1993) The Practical Handbook of Compost Engineering. CRC Publishers Ltd., Boca Raton, Florida, USA.

13. Kalemelawa, F., Nishihara, E., Endo, T., Ahmad, Z., Yeasmin, R., Tenywa, M. M., Yamamoto, S. (2012) An Evaluation of Aerobic and Anaerobic Composting of Banana Peels Treated With Different İnoculums for Soil Nutrient Replenishment, Bioresource Technology, 126, 375-382. doi:10.1016/j.biortech.2012.04.030

14. Khalil, A. I, Hassouna, M. S, El-Ashqar, H. M. A., Fawzi, M. (2011) Changes in physical, chemical and microbial parameters during the composting of municipal sewage sludge, World Journal of Microbiology and Biotechnology, 27(10), 2359-2369. doi: 10.1007/s11274-011-0704-8

15. Keeney, D. R. and Nelson, D. W. (1982) Nitrogen-inorganic forms in Methods of Soil Analysis, Part 2. Chemical and Microbiological Properties, (ed A.L. Page), 643-693, SSSA Book Series No 9, Soil Science Society of America and American Society of Agronomy, Madison, WI.

16. KT, (2015). Kompost Tebliği, T.C. Resmi Gazete, 29286, 5 Mart 2015.

17. Kumar, M., Ou, Y. L., Lin, J. G. (2010) Co-composting of green waste and food waste at low C/N ratio, Waste Management, 30, 602-609. doi:10.1016/j.wasman.2009.11.023

18. Li, S., Huang, G. H., An, C. J., Yu, H. (2013) Effect of different buffer agents on in-vessel composting of food waste: Performance analysis and comparative study, Journal Environmental Science and Health.Part A Toxic/Hazardous Substances \&Environmental Engineering, 48 (7), 772-780. doi:10.1080/10934529.2013.744637 
19. Mirabella, N., Valentina, C., Sala, S. (2014) Current options fort he valorization of food manufacturing waste: a review, Journal of Cleaner Production, 65, 28-41. doi: 10.1016/j.jclepro.2013.10.051

20. Mc Lean, E. O. (1982) Soil pH and Lime Requirement in Methods of Soil Analysis, Part 2. Chemical and Microbiological Properties, (A.L. Page, ed.), ASA-SSSA. Madison, Wisconsin, USA, 199-223.

21. Nikaeen, M., Nafez, A. H., Bina, B., Nabavi, B. F., Hassanzadeh, A. (2015) Respiration and enzymatic activities as indicators of stabilization of sewage sludge composting, Waste Management, 39, 104-110. doi: 10.1016/j.wasman.2015.01.028

22. Okalebo, J. R., Gathua, K. W., Woomer, P. L. (1993) Laboratory methods of soil and plant analysis: a working manual, TSBF programe, Soil Science Society of East Africa technical publication no. 1, UNESCO, Rosta, Kenya.

23. Paredes, S. C., Bernal, M. P., Cegarra, J., Roig, A. (2002) Bio-degradation of Olive Mill Wastewater Sludge by its Co-Composting With Agriculturalwastes, Bioresource Technology, 85, 1-8. doi:10.1016/S0960-8524(02)00078-0

24. Rhoades, J. D. (1982) Soluble Salts in Methods of Soil Analysis, Part 2, Chemical and Microbiological Properties, (A.L. Page, ed.), ASA-SSSA. Madison, Wisconsin, USA, 167178.

25. Uçaroğlu, S. (2014) Use of Sunflower Stalks as a Bulking Agent in Sewage Sludge Composting, Fresenius Environmental Bulletin 23(6): 1302-1308. doi:10.3291/F-2013$546 \mathrm{pj} 2014$

26. Uçaroğlu S., Alkan S. (2016) Composting of wastewater treatment sludge with different bulking agents, Journal of the Air \& Waste Management Association, 66(3), 288-295. doi:10.1080/10962247.2015.1131205

27. USEPA, (1993). Standards for the Use and Disposal of Sewage, 40 CFR Parts 257, 403, and 503 (FRO-4203-3), Final Rule, Fed. Register, 58, 9248, US Government Printing Office, Washington, DC. February 19.

28. Wang, X., Cui, H., Shi, J., Zhao, X., Zhao, Y., Wei, Z. (2015) Relationship between bacterial diversity and environmental parameters during composting of different raw materials, Bioresource Technology, 198, 395-402. doi:10.1016/j.biortech.2015.09.041

29. Yağcı, S., Altan, A., Göğüş, F., Maskan, M. (2006) Gıda Atıklarının Alternatif Kullanım Alanlar1, Türkiye 9. Gıda Kongresi, Bolu.

30. Yu, H., Huang, G. H. (2009) Effects of sodium acetate as a pH control amendment on the composting of food waste, Bioresource Technology, 100, 2005-2011. doi:10.1016/j.biortech.2008.10.007

31. Yang, F., Li, G., Shi, H., Wang, Y. (2015) Effects of phosphogypsum and superphosphate on compost maturity and gaseous emissions during kitchen waste composting, Waste Management, $\quad 36, \quad 70-76 . \quad$ doi:10.1016/j.wasman.2014.11.012 
